\title{
REVISTA BRASILEIRA DE
}

AGRICULTURA IRRIGADA

Revista Brasileira de Agricultura Irrigada v.10, nº.3, p. 640 - 650, 2016

ISSN 1982-7679 (On-line)

Fortaleza, CE, INOVAGRI - http://www.inovagri.org.br

DOI: $10.7127 /$ rbai.v10n300390

Protocolo 390.16 - 17/12/2015 Aprovado em 01/06/2016

\section{QUALIDADE DA ÁGUA DRENADA E DESENVOLVIMENTO DO FEIJÃO-CAUPI EM SOLOS SALINO-SÓDICOS APÓS USO DE GESSO ASSOCIADO À LÂMINA DE LIXIVIAÇÃO}

Ricardo Rafael Andrade de Vasconcelos ${ }^{1}$; Erika Socorro Alves Graciano²; Angela Jessyka Pereira Brito Fontenele ${ }^{3}$; Aluízio Tavares Cordeiro neto ${ }^{4}$; Maria de Fatima Cavalcanti Barros ${ }^{5}$

\section{RESUMO}

A salinização e a sodificação dos solos representam dois dos principais problemas das áreas cultivadas na região semiárida do Nordeste brasileiro, responsáveis pela redução da produção agrícola. O objetivo deste trabalho foi avaliar a influência do uso de diferentes níveis de gesso associado à lâmina de lixiviação parcelada em dois solos salino-sódicos sobre a qualidade da água de drenagem e no desenvolvimento do feijão-caupi. Para o estudo foram utilizadas colunas de PVC, as quais foram preenchidas com amostras de dois Neossolo Flúvico, conduzido em delineamento em blocos casualizados, com cinco níveis de necessidade de gesso (50, 100, 150, 200 e 250\%) associados a uma lâmina de lixiviação, com cinco repetições. Após a aplicação do gesso e da lâmina de lixiviação, os solos foram cultivados com feijão-caupi. Na água drenada foi analisada a concentração de sódio solúvel, condutividade elétrica e $\mathrm{pH}$. $\mathrm{Na}$ planta foi avaliada a altura e produção de biomassa seca. A aplicação de diferentes níveis de necessidade de gesso associada à lâmina de lixiviação parcelada favorece a remoção do sódio solúvel dos solos. A lâmina de lixiviação equivalente a três volumes de poros possibilita correção da salinidade do solo S2, quando utilizado os níveis de 50 e $100 \%$ da necessidade de gesso, podendo ser cultivado com feijão-caupi, sem prejudicar a altura e produção de biomassa das plantas.

Palavras-chaves: condutividade elétrica; sódio solúvel; salinidade; sodicidade.

\section{QUALITY OF DRAINED AND DEVELOPMENT OF COWPEA IN SALINE-SODIC SOILS AFTER GYPSUM USE ASSOCIATED WITH LEACHING BLADE}

\footnotetext{
ABSTRACT

${ }^{1}$ Programa de Pós-Graduação em Engenharia Agrícola, UFRPE. E-mail: ricardoandrade86@gmail.com

${ }^{2}$ Programa de Pós-Graduação em Ciência do Solo, UFRPE. E-mail: erikagraciano@gmail.com

${ }^{3}$ Programa de Pós-Graduação em Engenharia Agrícola, UFRPE. E-mail: jessykafontenele@hotmail.com

${ }^{4}$ Programa de Pós-Graduação em Engenharia Agrícola, UFRPE. E-mail: aluiziotcn@hotmail.com

${ }^{5}$ Departamento de Agronomia, UFRPE, R. Manuel de medeiros, s/n, CEP 52171-900, Recife-PE, Brasil. E-mail: barrosmfatima@hotmail.com
} 
The salinization and sodification represent two of the main problems of the areas cultivated in the semiarid region of northeastern Brazil, responsible for the reduction of agricultural production. The objective of this study was to evaluate the influence of using different gypsum levels associated with parceled leaching blade in two saline-sodic soils on drainage water quality and the development of cowpea. For the study was using PVC columns, which were filled with samples from two Fluvic Neossol conducted in a randomized block design, with five levels of need for gypsum (50, 100, 150, 200 and 250\%) associated with a blade leaching, with five repetitions. After application of gypsum and leaching blade, the soils were cultured with cowpea. The drained water was analyzed the concentration of soluble sodium, electrical conductivity and $\mathrm{pH}$. The plant height was measured and the production of dry biomass. The application of different levels need gypsum associated with leaching split blade sodium favors the removal of soluble soils. The blade leaching equivalent to three volumes of pores allows soil salinity correction S2 when used levels of 50 and $100 \%$ of the need of gypsum, can be cultivated with cowpea, not harming the height and biomass production of plants.

Keywords: Electric conductivity; sodium soluble; salinity; sodicity.

\section{INTRODUÇÃO}

A salinização e sodificação representam dois dos principais problemas das áreas cultivadas na região semiárida do Nordeste brasileiro, responsáveis pela redução da produção agrícola, culminando na maioria das vezes com a degradação e o abandono de áreas agricultáveis, originando prejuízos à economia da região (MELO et al., 2008). A degradação dos solos cultivados no semiárido pela salinização e sodificação ocorre, principalmente, devido às condições climáticas da região, que são caracterizadas com altas temperaturas, baixa pluviosidade e altas taxas de evaporação (RUIZ et al., 2004; DIAS et al., 2007); a qualidade da água utilizada para atender as exigências hídricas das culturas (LACERDA et al., 2011) e o manejo inadequado das práticas de irrigação associado à falta ou deficiência de sistema de drenagem (TAVARES FILHO et al., 2012).

O alto nível de sais no solo promove redução do potencial osmótico da solução do solo, comprometendo a disponibilidade e absorção de água e nutrientes pelas plantas, causando desbalanço nutricional (ARAÚJO et al., 2011), afetando, assim, o crescimento e a produtividade das plantas (GRACIANO et al., 2011). E o alto nível de sódio no solo pode causar toxidez nas plantas e o impedimento da germinação de sementes (SMITH et al., 2009), além de afetar as propriedades químicas e físicas dos solos (SILVA et al. 2005; GARCIA et al., 2008), ocasionando dispersão da argila e degradação da estrutura dos solos, tornando-os impermeáveis (RUIZ et al., 2004) e impróprio para utilização agrícola.

A recuperação dos solos afetados por salinização e sodificação é de fundamental importância para reincorporação dessas áreas ao sistema produtivo (MELO et al., 2008), podendo contribuir para aumento da renda dos agricultores. A recuperação dos solos salinosódicos tem como objetivo a diminuição da concentração dos sais solúveis e do sódio trocável no perfil do solo, deixando o solo apto para agricultura. A salinidade pode ser reduzida através do processo de solubilização e lixiviação dos sais ao longo do perfil do solo, já a diminuição da sodicidade requer a substituição do sódio trocável por cálcio e que o produto dessa reação seja removido da zona radicular por lixiviação (BARROS et al., 2004). O gesso tem sido a fonte de cálcio mais utilizada para recuperação da sodicidade dos solos, por apresentar menor custo, fácil manuseio e maior disponibilidade no mercado (MELO et al., 2008; ARAÚJO et al., 2011).

Os solos salino-sódicos, embora apresentem uma elevada concentração de sódio possuem permeabilidade menos crítica do que os solos sódicos, em razão do efeito floculante dos sais. A retirada imediata dos sais presentes nestes solos, antes que o corretivo aplicado tenha sua maior parte solubilizada, pode 
ocasionar severa redução da drenagem e, consequentemente, inviabilizá-los para a atividade agrícola (RUIZ et al., 2004). Assim, o sucesso da recuperação solos salino-sódicos pode ser obtido através da utilização de práticas adequadas de irrigação com o parcelamento da lâmina de lixiviação combinado com uso de gesso.

Na literatura, estudos para a recuperação de solos salino-sódicos, utilizando o gesso, tem como finalidade principal os efeitos deste corretivo nas propriedades químicas dos solos (LEITE et al., 2007; GARCIA et al., 2008; BARROS et al., 2009; TAVARES FILHO et al., 2012), entretanto, são escassas as informações sobre a qualidade da água drenada em solos salino-sódicos após a aplicação deste corretivo, e pouco se conhece sobre o comportamento de culturas agrícolas nesses solos após o uso de corretivo associado com lâmina de lixiviação parcelada. Desta forma, o trabalho teve como objetivo avaliar a influência do uso de diferentes níveis de gesso associado à lâmina de lixiviação parcelada em dois solos salino-sódicos sobre a qualidade da água drenada e o desenvolvimento do feijão-caupi.

\section{MATERIAL E MÉTODOS}

O trabalho foi desenvolvido em duas etapas: a primeira em laboratório, para avaliar o efeito do uso de diferentes níveis de necessidade de gesso associado à lâmina de lixiviação parcelada na qualidade da água drenada de dois solos salino-sódicos, e a segunda em casa de vegetação, para avaliar o desenvolvimento do feijão-caupi nos solos após a aplicação de gesso associado à lâmina de lixiviação parcelada.

Neste trabalho foi utilizado amostras de dois Neossolo Flúvico (S1 e S2), com problemas de sais e sódio trocável, localizadas em lotes do Perímetro Irrigado do Moxotó, no município de Ibimirim-PE, as coordenadas geográficas estão a latitude $08^{\circ} 32^{\prime} 26^{\prime \prime}$ Sul, longitude $37^{\circ} 41^{\prime} 25^{\prime}$ ' Oeste, a 401 metros de altitude, com uma área de $2.033,593 \mathrm{Km}^{2}$. As amostras de solo foram coletadas seguindo procedimento descrito por Magalhães (1987) modificado por Barros (2001), na profundidade de 0-40 cm. Após a coleta, as amostras de solo foram conduzidas ao laboratório de Mecânica do Solo e Aproveitamento de Resíduos da Universidade Federal Rural de Pernambuco, onde foram colocadas para secar ao ar, destorroadas e passadas em peneira de $2 \mathrm{~mm}$ de abertura da malha para caracterização química e física dos solos. Antes do procedimento de destorroar, foram retirados alguns torrões das amostras para determinação da densidade do solo.

Para caracterização química dos solos, foi obtida a pasta saturada seguindo a metodologia descrita por Richard (1954); determinando-se no extrato da pasta saturada a condutividade elétrica (CE); os íons solúveis de cálcio e magnésio por espectrofotometria de absorção atômica, de sódio e potássio por fotometria de emissão de chama (EMBRAPA, 1997). Com os valores obtidos de cálcio, magnésio e sódio solúveis, foi calculada a relação de adsorção de sódio (RAS), pela seguinte equação 1:

$$
\mathrm{RAS}=\frac{\mathrm{Na}^{+}}{\sqrt{\frac{\left(\mathrm{Ca}^{2+}+\mathrm{Mg}^{2+}\right)}{2}}}
$$

Foram determinados, também, pela metodologia de Richard (1954) o pH dos solos utilizando relação solo-água de 1:2,5; a capacidade de troca de cátions (CTC) pelo método de acetato de sódio e o sódio trocável extraído com a solução de acetato de amônio 1 mol L $\mathrm{L}^{-1}$ a pH 7,0. A necessidade de gesso (NG) do solo foi determinada utilizado o método de laboratório de Schoonover M-1 modificado por Barros e Magalhães (1989) para solos salinosódicos de Pernambuco.

Para caracterização física dos solos foi determinada a densidade do solo, pelo método do torrão parafinado (EMBRAPA, 1997); a densidade de partículas, pelo método do balão volumétrico (EMBRAPA, 1997); a porosidade total (EMBRAPA, 1997); a composição granulométrica, após lavagem do solo com etanol a $60 \%$ até eliminação total de cloretos (BOYOUCOS, 1962); a argila dispersa em água (BOYOUCOS, 1962) e a taxa de infiltração de água nas amostras dos solos dentro das colunas foi realizada com base na equação 2: 


$$
\mathrm{TI}=\frac{\Delta \mathrm{q}}{\Delta \mathrm{t}}
$$

Em que:

$\mathrm{TI}=$ taxa de infiltração $\left(\mathrm{cm} \mathrm{h}^{-1}\right)$;
$\Delta \mathrm{q}=$ volume do infiltrado $(\mathrm{ml})$ e $\Delta \mathrm{t}=$ tempo $(\mathrm{h})$.

Os resultados da caracterização química e física das amostras de solos estão apresentados nos Tabela 1 e 2.

Tabela 1. Características químicas de dois solos salino-sódicos do semiárido de Pernambuco, Brasil.

\begin{tabular}{|c|c|c|c|c|c|c|c|c|c|c|}
\hline \multirow{2}{*}{ Solos } & \multicolumn{4}{|c|}{ Íons solúveis } & \multirow{2}{*}{$\mathrm{CE}$} & \multirow{2}{*}{ RAS } & \multirow{2}{*}{$\mathrm{pH}$} & \multirow{2}{*}{ CTC } & \multirow{2}{*}{$\begin{array}{l}\mathrm{Na}^{+} \\
\text {trocável }\end{array}$} & \multirow{2}{*}{ NG } \\
\hline & $\mathrm{Ca}^{2+}$ & $\mathrm{Mg}^{2+}$ & $\mathrm{Na}^{+}$ & $\mathrm{K}^{+}$ & & & & & & \\
\hline & \multicolumn{4}{|c|}{---------(mmol $\left.\mathrm{m}_{\mathrm{C}} \mathrm{L}^{-1}\right)--------$} & $\left(\mathrm{dS} \mathrm{m} \mathrm{m}^{-1}\right)$ & $\left(\mathrm{mmol} \mathrm{L}^{-1}\right)$ & & \multicolumn{3}{|c|}{------ $\left(\mathrm{cmol}_{\mathrm{C}} \mathrm{dm}^{-3}\right)$----- } \\
\hline S1 & 136,51 & 8,39 & 489,36 & 3,30 & 60,61 & 57,49 & 7,18 & 13,52 & 8,13 & 9,38 \\
\hline S2 & 69,40 & 5,63 & 291,65 & 3,71 & 36,16 & 47,62 & 7,10 & 9,62 & 4,75 & 7,19 \\
\hline
\end{tabular}

CE - condutividade elétrica; RAS - Relação de adsorção atômica; pH - relação 1:2,5; CTC - capacidade de trocas de cátions; NG Necessidade de Gesso.

Tabela 2. Características físicas de dois solos salino-sódicos do semiárido de Pernambuco, Brasil.

\begin{tabular}{|c|c|c|c|c|c|c|c|c|c|}
\hline \multirow[t]{2}{*}{ Solos } & \multirow[t]{2}{*}{$\mathrm{Dp}$} & \multirow[t]{2}{*}{ Ds } & \multicolumn{3}{|c|}{$\begin{array}{c}\text { Análise } \\
\text { Granulométrica }\end{array}$} & \multirow{2}{*}{$\begin{array}{l}\text { Classificação } \\
\text { Textural }\end{array}$} & \multirow[t]{2}{*}{ TI } & \multirow[t]{2}{*}{ PT } & \multirow[t]{2}{*}{ GD } \\
\hline & & & Areia & Silte & Argila & & & & \\
\hline & \multicolumn{2}{|c|}{$\left(\mathrm{kg} \mathrm{dm}^{-3}\right)$} & \multicolumn{3}{|c|}{------(g.gk' } & & $\left(\mathrm{cm} \cdot \mathrm{h}^{-1}\right)$ & \multicolumn{2}{|c|}{----(\%)---- } \\
\hline S1 & 2,52 & 1,36 & 139 & 562 & 299 & Franco-Argilo-Siltoso & 0,0 & 46,03 & 80,50 \\
\hline $\mathrm{S} 2$ & 2,45 & 1,45 & 342 & 415 & 243 & Franco & 0,0 & 40,82 & 69,40 \\
\hline
\end{tabular}

Para a realização do experimento foram utilizadas colunas de PVC com $30 \mathrm{~cm}$ de altura e $10 \mathrm{~cm}$ de diâmetro, tendo uma das extremidades fechada com um tampão adaptado com uma torneira de 3/8 polegada no centro para a coleta da solução drenada. As colunas foram divididas em duas camadas de $12,5 \mathrm{~cm}$ de altura cada. Os solos foram acondicionados nas colunas de modo a aproximar do valor da densidade do solo em condições de campo. As colunas foram preenchidas inicialmente com o solo da camada de 12,5 - 25,0 cm e, posteriormente, da camada $0,0-12,5 \mathrm{~cm}$. O gesso foi incorporado na primeira camada $(0,0$ $12,5 \mathrm{~cm}$ ) antes do acondicionamento.

O experimento foi conduzido em delineamento em blocos casualizados, com cinco níveis de necessidade de gesso (50, 100, 150, 200 e 250\%) associados a uma lâmina de lixiviação parcelada (3 volumes de poros do solo), com cinco repetições. Os solos foram mantidos nas colunas com umidade da capacidade de campo por 24 horas, coberto com papel filme. Após esse período foi aplicada a lâmina de lixiviação, correspondendo a três vezes o volume de poros do solo (1VP, $2 \mathrm{VP}$ e
3VP), onde cada volume de poros, com lâmina de 95,6 mm, foi aplicado com um intervalo de cinco dias. Neste intervalo, as colunas também foram cobertas com papel filme. Durante a aplicação de cada volume de poros, a água lixiviada foi coletada e realizada a determinação da concentração de sódio solúvel, a condutividade elétrica e o $\mathrm{pH}$.

Após a coleta da água drenada, as colunas foram desmontadas e os solos foram secos ao ar, destorroados, passados em peneira 2 $\mathrm{mm}$ de abertura da malha e colocados em vasos de polietileno (sem cavidade para drenagem de água) e levados para casa de vegetação. Em cada vaso foi adicionado $2 \mathrm{~kg}$ de solo e plantadas cinco sementes de feijão-caupi (cultivar pele de moça) inoculadas com estirpe de Bradyrhizobium japonicum. Antes do plantio, as sementes foram submetidas a processo de desinfestação, onde as quais foram imersas em álcool a 70\% por um minuto; em seguida, imersas em hipoclorito de sódio a $1 \%$ por 30 segundos, e, por último, lavadas em água destilada por sete vezes. Para a inoculação das sementes foi utilizado um inoculante turfoso contendo as estirpes BR 3267 e SEMIA 6462. 


\section{SÓDICOS APÓS USO DE GESSO ASSOCIADO À LÂMINA DE LIXIVIAÇÃO}

As sementes foram plantadas diretamente nos vasos com auxílio de um bastão de vidro com controle de profundidade de $1 \mathrm{~cm}$ da superfície. Após sete dias do plantio foi realizado um desbaste, deixando duas plantas por vaso. Os solos nos vasos foram mantidos diariamente com umidade entre 70 a $80 \%$ da capacidade de campo.

Após 40 dias do plantio foi determinada a altura das plantas e, em seguidas, elas foram colhidas para determinação da produção de biomassa seca da parte aérea. A altura das plantas foi determinada com auxílio de uma trena. Para determinação da produção de biomassa seca da parte aérea, a parte aérea das plantas foi colhida, acondicionada em saco de papel, levada para secagem em estuda com ventilação forçada a $65^{\circ} \mathrm{C}$ (até atingir peso constante) e pesadas em balança de $0,01 \mathrm{~g}$ de precisão.
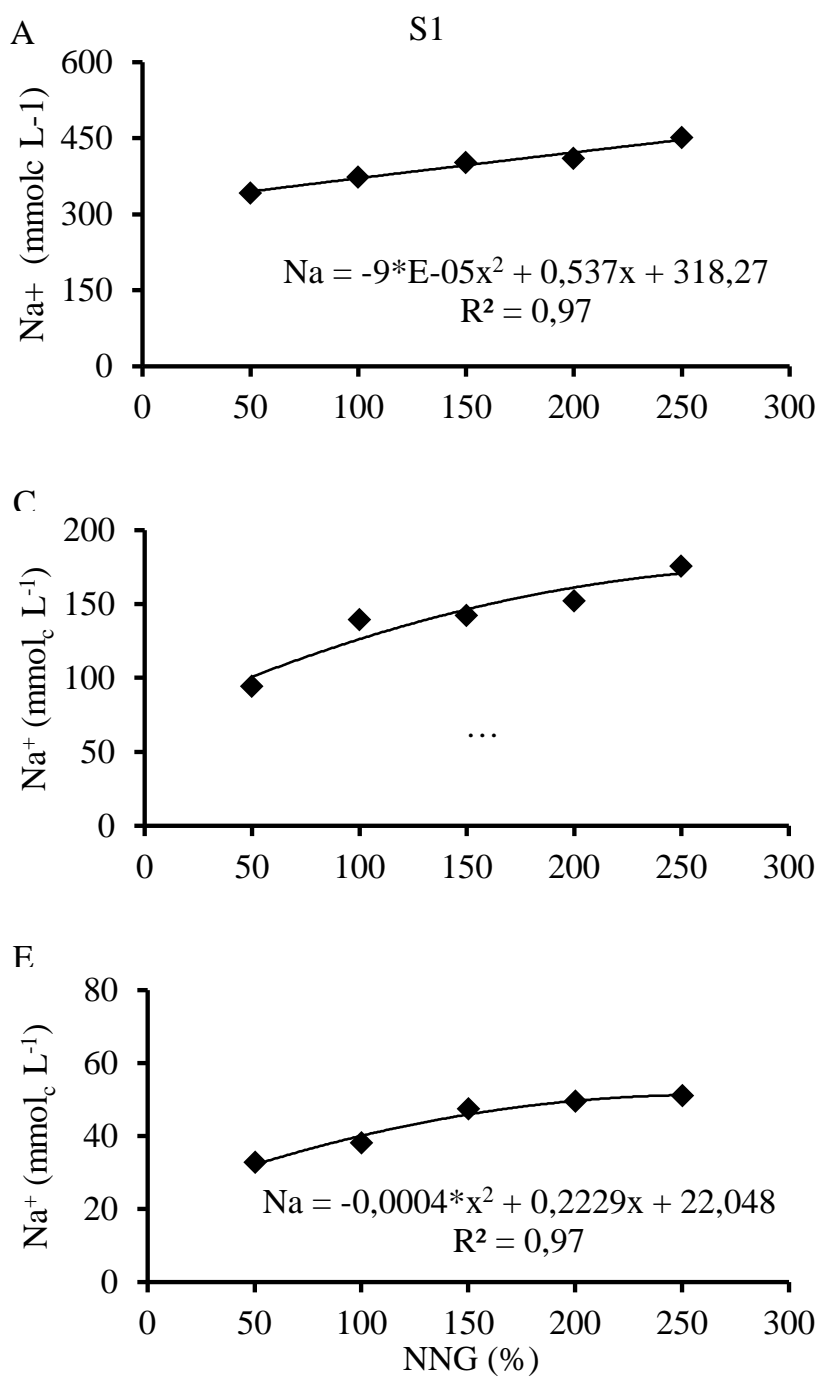

Os dados obtidos foram submetidos à análise de variância e de regressão, utilizando o modelo com maior valor de coeficiente de determinação, precedido da significância dos coeficientes da equação de regressão.

\section{RESULTADOS E DISCUSSÕES}

A concentração de sódio solúvel da água drenada dos solos S1 e S2 aumentou com a aplicação de níveis de necessidade de gesso (NNG) associada à lâmina de lixiviação, equivalente a três vezes o volume de poros, parcelada (Figura 1), indicando remoção de sódio presente nos solos. As relações entre NNG e sódio solúvel dos solos $\mathrm{S} 1$ e S2 nos três volumes de água drenada (1VP, 2VP e 3VP) ajustaram-se significativamente ao modelo polinomial de $2^{\circ}$ ordem, apresentando alto coeficiente de determinação $\left(\mathrm{R}^{2} \geq 0,90\right)$.

B

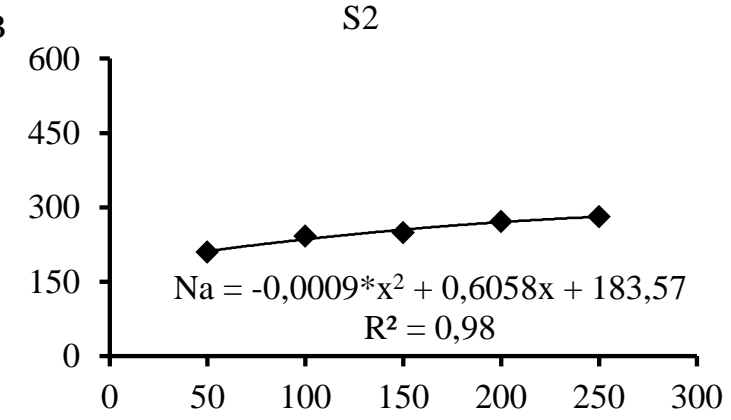

D

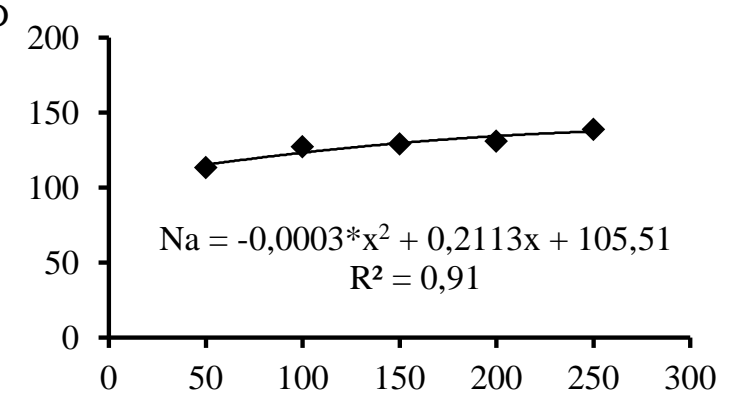

$\mathrm{F}$

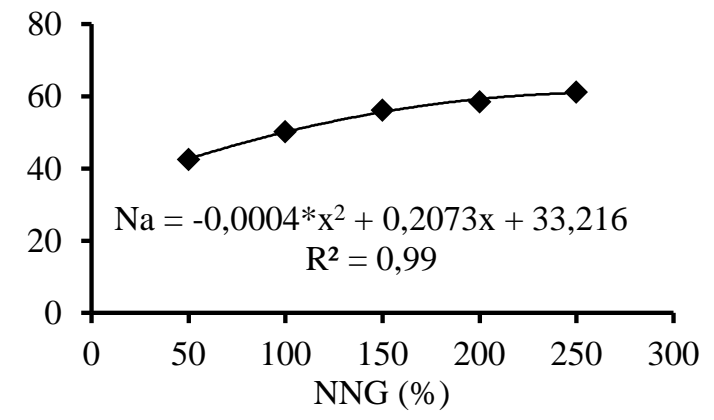


Figura 1. Regressão para teor de sódio solúvel da água drenada de dois solos salino-sódicos (S1 e S2) após aplicação de diferentes níveis de necessidade de gesso (NNG) associado à lâmina de lixiviação parcelada em um (A e B), dois (C e D) e três volumes de poros (E e F).

O primeiro volume de água drenada dos solos S1 e S2 (Figura 1A, B) apresentou a maior concentração de sódio solúvel em relação aos demais volumes de água drenada (2VP e 3VP), com valores próximos aos encontrados no extrato da pasta saturada antes da aplicação do gesso (Tabela 1). A menor concentração de sódio solúvel no segundo volume de água drenada (Figura 1C, D) e no terceiro volume (Figura 1E, F) dos solos pode estar relacionada à remoção do sódio solúvel presente nos microporos do solo, como também do sódio advindo das reações de troca iônica entre o cálcio da solução e o sódio ligado ao complexo de troca. Esses resultados corroboram com os resultados obtidos por Tavares Filho et al., (2012), estudando a incorporação de gesso para correção da salinidade e sodicidade de solos salino-sódicos, observaram diminuição dos valores de sódio solúvel pelo aumento da aplicação dos níveis da necessidade de gesso seguida da aplicação de lamina de lixiviação.

A condutividade elétrica (CE) apresentou comportamento semelhante à concentração do sódio solúvel nos três volumes de água drenada. As relações entre CE e NNG dos solos nos três volumes de água drenada ajustaram-se significativamente ao modelo quadrático, com altos coeficientes de determinação entre os níveis da necessidade de gesso $\left(\mathrm{R}^{2} \geq 0,95\right)$ (Figura 2). A CE do primeiro volume de água drenada apresentou uma alta concentração de sais (Figura 2A, B) quando comparada com a CE do extrato de saturação dos solos S1 e S2 (Tabela 1). A CE do primeiro volume de água drenada do solo S1 aumentou com o aumento dos níveis de necessidade de gesso (Figura 2A). Esse resultado, possivelmente, ocorreu pelo efeito da aplicação crescente dos níveis de gesso que proporcionou a retirada dos sais e, consequentemente, um acúmulo de sais no lixiviado.

$\mathrm{O}$ segundo e o terceiro volume de água drenada dos solos S1 e S2 apresentaram CE bem mais baixas que a do primeiro volume (Figura 2C, D), isso ocorre provavelmente devido à diminuição do efeito da solubilização do gesso associada a lâminas de lixiviação aplicadas às amostras de solos. Este efeito foi semelhante ao encontrado por Silveira et al. (2008) trabalhando com correção da sodicidade de solos irrigados em respostas à aplicação de gesso, esses autores observaram que os primeiros lixiviados coletados das colunas de solo apresentavam os maiores valores de $\mathrm{CE}$, decrescendo drasticamente até igualar a CE da água usada na irrigação. 

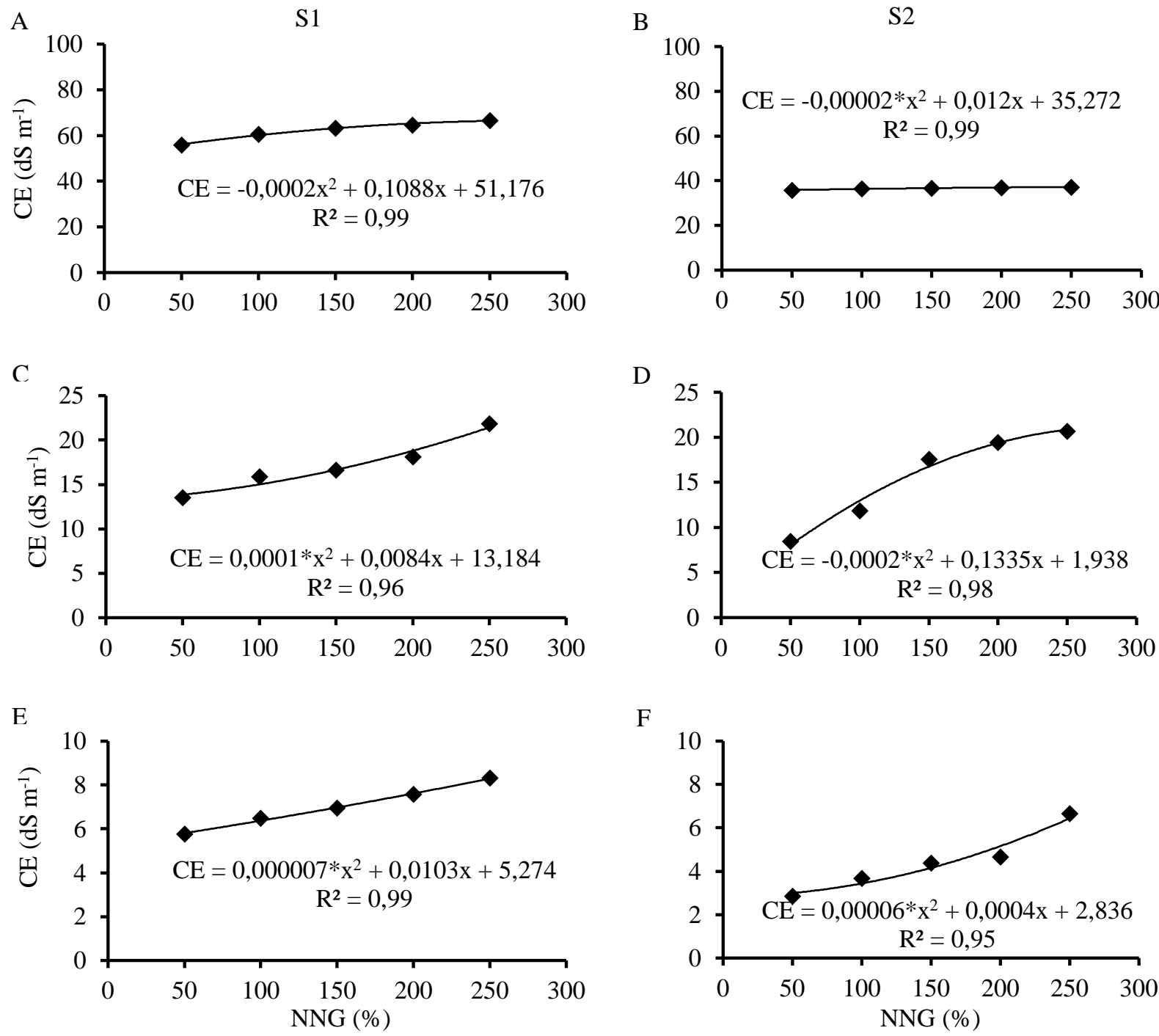

Figura 2. Condutividade elétrica da água drenada de dois solos salino-sódicos (S1 e S2) após aplicação a diferentes níveis da necessidade de gesso (NNG) associado à lâmina de lixiviação parcelada em um (A e B), dois (C e D) e três volumes de poros (E e F).

Gheyi et al. (1995) avaliando diferentes métodos na recuperação de solo salino-sódico, relatam que o gesso interfere na salinidade dos solos, aumentando-a inicialmente pela liberação dos eletrólitos e reduzindo-a ao longo do tempo mediante o aumento da permeabilidade do solo, que favorece a infiltração e a redistribuição da água no perfil do solo, e consequentemente a lixiviação dos sais. As modificações na concentração de sódio e sais, expressa pela CE da água drenada, obtidas neste trabalho (Figuras 1 e 2) comprovam a eficiência do gesso e do parcelamento da lâmina de lixiviação de três volumes de poros na correção da sodicidade e salinidade dos solos avaliados.
Na Figura 3 estão apresentados os valores de $\mathrm{pH}$ nos três volumes de água drenada em função dos NNG aplicados. A relação entre o pH e NNG se ajustou ao modelo quadrático, apresentando alto coeficiente de determinação da variável em estudo, variando entre 0,96 a 0,99 para o solo S1 e 0,98 a 0,99 para o solo S2. O $\mathrm{pH}$ dos três volumes de água drenada dos solos S1 e S2 aumentou com o aumento dos NNG (Figura 3).

Os resultados obtidos de $\mathrm{pH}$ no segundo (Figura 3C, D) e no terceiro volume de água drenada (Figura 3E, F) dos solos S1 e S2, respectivamente, apresentaram comportamentos opostos aos obtidos para condutividade elétrica e sódio solúvel, enquanto que os valores da CE 
e do sódio diminuíram, em relação ao primeiro volume de água drenada, com a aplicação das lâminas de lixiviação, os valores de $\mathrm{pH}$ tiveram um ligeiro incremento. É possível que este aumento esteja relacionado com a diminuição da

A

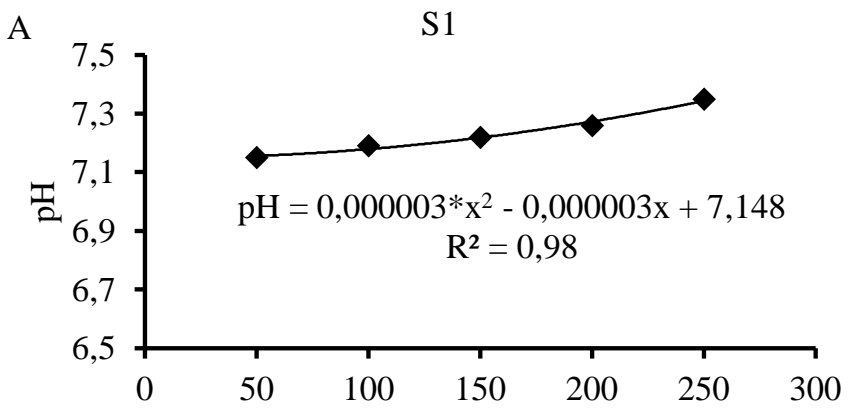

$\Gamma$

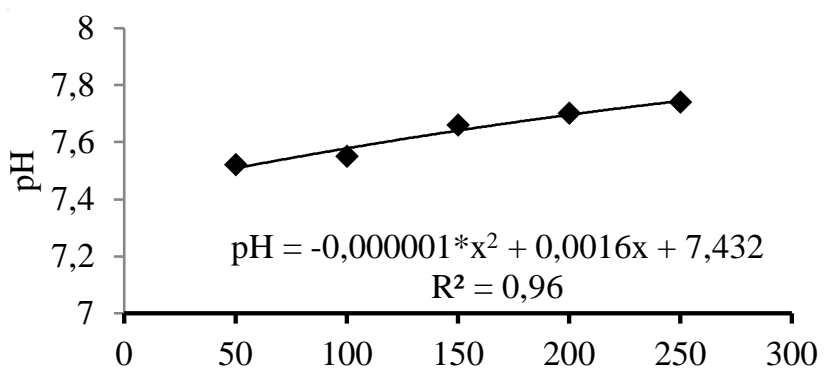

F

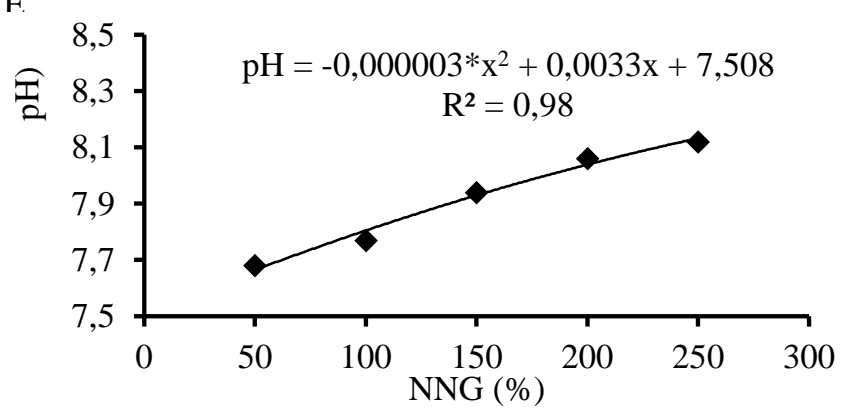

concentração total de sais e com predominância de sódio em relação aos cátions de hidrogênio presentes na solução, concordando desta forma com os resultados observados por Barros (2001) e Silveira et al. (2008).

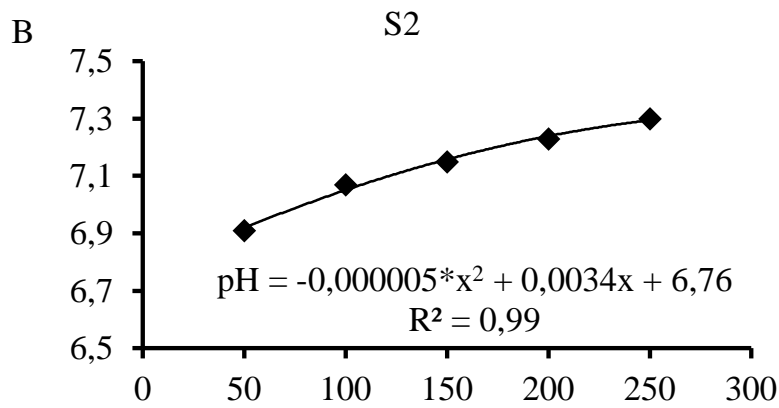

D

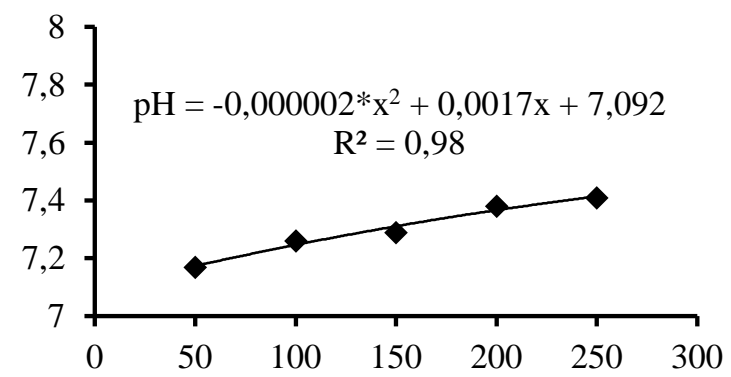

F

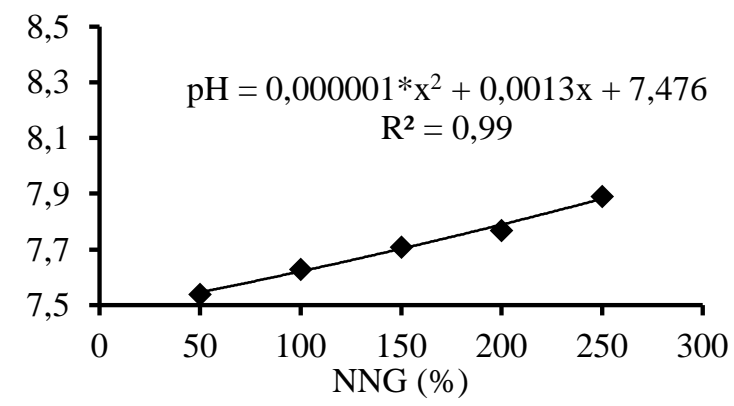

Figura 3. Valores de pH da água drenada de dois solos salino-sódicos (S1 e S2) após aplicação a diferentes níveis da necessidade de gesso (NNG) associado à lâmina de lixiviação parcelada em um (A e B), dois (C e D) e três volumes de poros (E e F).

O desenvolvimento do feijão, avaliado pela altura e produção de biomassa seca da parte aérea da planta, nos solos S1 e S2 após aplicação de diferentes NNG associada à lâmina de lixiviação parcelada está apresentado na figura 4. A relação entre altura da planta e NNG e biomassa seca da parte aérea e NNG, também, ajustaram-se ao modelo quadrático apresentando coeficiente de determinação para a altura da planta com valores de 0,89 e 0,99 e para biomassa seca de 0,99 e 0,70 para o solo para o solo S1 e S2, respectivamente. A altura da planta de feijão cultivada no solo S1 após aplicação de 100 e 150\% de necessidade de gesso (NG) associada à lâmina de lixiviação parcelada apresentou aumento, em seguida um decréscimo nos NNG de 200 e 250\% (Figura 4A); e a altura das plantas de feijão cultivadas no solo S2 aumentou em função do aumento dos NNG (Figura 4B). E a produção de biomassa seca da parte aérea das plantas de feijão cultivadas nos solos S1 e S2 apresentou comportamento semelhante ao resultado da altura da planta (Figura 4C, D) 

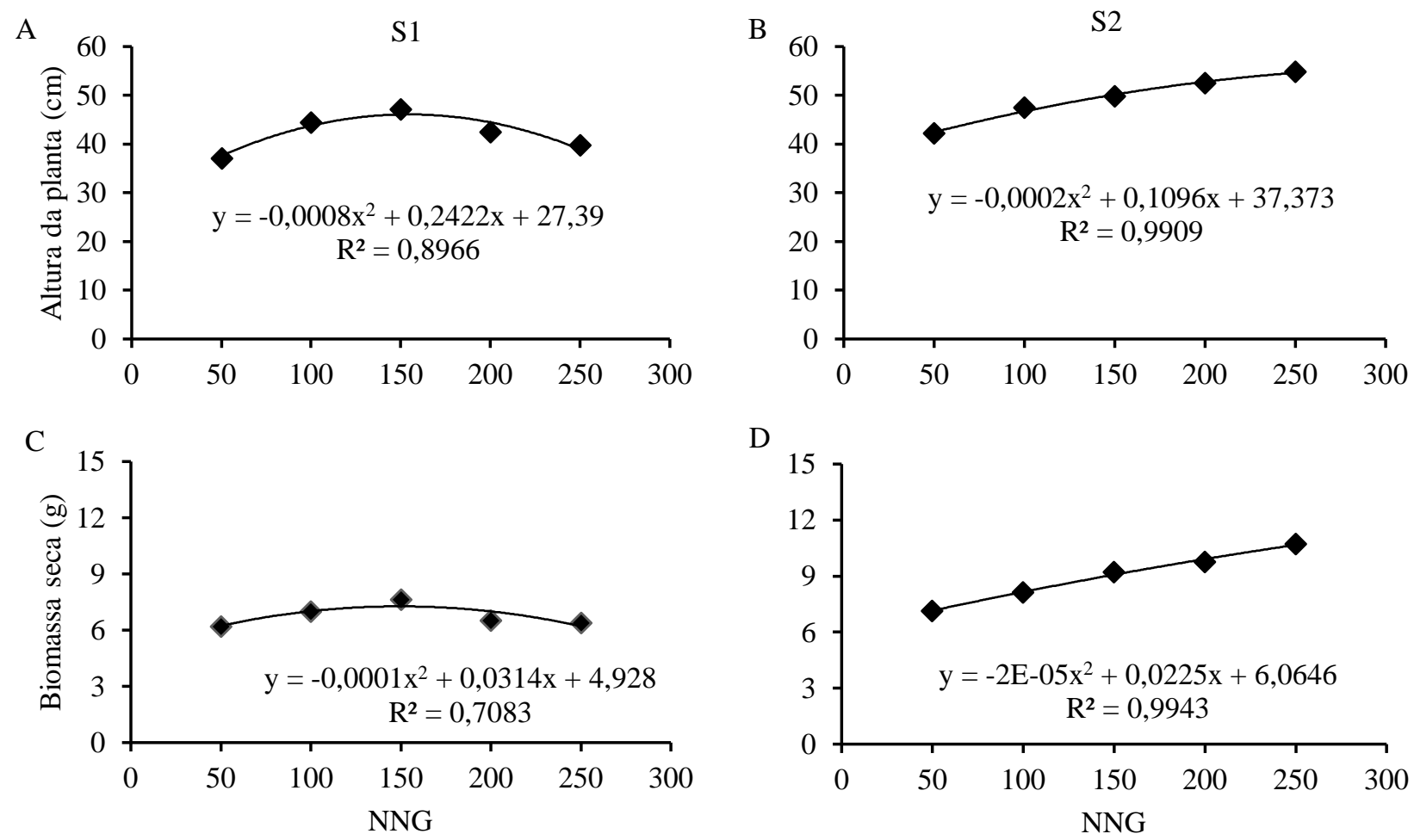

Figura 4. Altura e biomassa seca da parte aérea de planta de feijão cultivado em solos salino-sódicos (S1 e S2) após aplicação de diferentes níveis da necessidade de gesso (NNG) associado à lâmina de lixiviação de três volumes de poros.

Silva et al. (2011), avaliando a interação entre salinidade e biofertilizante bovino na cultura do feijão-caupi, constataram que os níveis crescentes de sais da água de irrigação prejudicaram o crescimento em altura de plantas de feijão-caupi (cultivar Epace 10). Silva et al. (2009), avaliando o efeito de diferentes níveis de salinidade da água de irrigação no desenvolvimento vegetativo do feijão-caupi em casa de vegetação, verificaram que a matéria seca total é afetada negativamente com a salinidade com CE de 4 a $5 \mathrm{dS} \mathrm{m}{ }^{-1}$. Sousa et al. (2014), avaliando o efeito do estresse salino em plantas de feijão-caupi em solo com fertilizantes orgânicos, verificaram que tanto a altura da planta quanto produção de matéria seca da parte área de feijão-caupi são afetadas negativamente com CE de 4,5 e 6,0 dS m ${ }^{-1}$.

O decréscimo da altura e da produção de biomassa seca da parte aérea das plantas de feijão cultivadas no solo S1 após a aplicação de 200 e $250 \%$ de NG observada neste trabalho, possivelmente, pode estar relacionado à presença de sais solúveis no solo, que não foram removidos totalmente com a lâmina de lixiviação, verificadas no resultado de CE da água drenada do solo S1 que apresentou valores acima de $7,5 \mathrm{dS} \mathrm{m}^{-1}$ após aplicação da terceira parcela da lâmina de lixiviação. A permanência dos sais no solo pode ter sido favorecida devido à textura do solo (Franco-argilo-siltoso) que apresenta maior porcentagem de argila. Para Lacerda et al. (2011), a redução da matéria seca da parte aérea em plantas de feijão-caupi sob condições de salinidade está relacionada ao desvio de energia em decorrência do alto nível de salinidade do solo; logo, a redução nos valores da matéria seca da parte aérea pode ser o reflexo do custo metabólico de energia.

\section{CONCLUSÕES}

A aplicação de diferentes níveis de necessidade de gesso, obtido pelo método de Schoonover M-1, associada a aplicação de lâmina de lixiviação parcelada favorece a 
remoção do sódio e sais solúveis dos solos salino-sódicos.

A lâmina de lixiviação equivalente a três volumes de poros corrige a salinidade do solo S2 quando utilizado os níveis de 50 e $100 \%$ da necessidade de gesso (CE $<4,00 \mathrm{dS} \mathrm{m^{-1 }}$ ), podendo ser cultivado com feijão-caupi, sem prejudicar a altura e produção de biomassa das plantas.

\section{REFERÊNCIAS}

ARAÚJO, A. P. B.; COSTA, R. N. T.; LACERDA, C. F.; GHEYI, H. R. Análise econômica do processo de recuperação de um solo sódico no perímetro irrigado CuruPentecoste, CE. Revista Brasileira de Engenharia Agrícola e Ambiental, v. 15, n. 4, p. 377-382, 2011.

BARROS, M. F. C.; FONTES, M. P. F.; ALVARES V., V. H.; RUIZ, H. A. Recuperação de solos afetados por sais pela aplicação de gesso de jazida e calcário no Nordeste do Brasil. Revista Brasileira de Engenharia Agrícola e Ambiental, v. 8, n. 1, p. 59-64, 2004.

BARROS, M. F. C.; MAGALÃES, A. F. Avaliações de métodos de determinação da necessidade de gesso em solos Salino-sódicos. Revista Brasileira de Ciência do Solo, v. 13, n. 2, p. 119-123, 1989.

BARROS, M. F. C. Recuperação de solos salino-sódicos pelo uso do gesso de Jazida e calcário. 2001. 112f. Tese (Doutorado em Solos e Nutrição de Planta) - Universidade Federal de Viçosa, Viçosa.

BARROS, M. F. C.; BEBÉ, F. V.; SANTOS, T. O.; CAMPOS, M. C. C. Influência da aplicação de gesso para correção de um solo salino-sódico cultivado com feijão caupi. Revista de Biologia e Ciências da Terra, v. 9, n. 1, p. 77-82, 2009.

BOYOUCOS, G. Y. Hydrometer method improved for making particle size analysis of soil. Agronomic Journal, v. 54, p. 454-455, 1962.
DIAS, N. S.; DUARTE, S. N.; TELES FILHO, J.F.; YOSHINAGA, R.T. Salinização do solo por aplicação de fertilizantes em ambientes protegido. Irriga, v. 12, n. 1, p. 135-143, 2007.

EMBRAPA - Empresa Brasileira de Pesquisa Agropecuária. Manual de Métodos de análises de solo. 2. ed. Rio de Janeiro: EMBRAPA, 1997. 211p.

GARCIA, G. O.; MARTINS FILHO, S.; REIS, E. F.; MORAES, W. B.; NAZÁRIO, A. A. Alterações químicas de dois solos irrigados com água salina. Revista Ciência Agronômica, v. 39, n. 1, p. 7-18, 2008.

GHEYI, H. R.; AZEVEDO, N. C.; BATISTA, M. A. F.; SANTOS, J. G. R. Comparação de métodos na recuperação de solo salinosódicos. Revista Brasileira de Ciência do Solo, v. 19, n. 2, p. 173-178, 1995.

GRACIANO, E. S. A.; NOGUEIRA, R. J. M. C.; LIMA, D. R. M.; PACHECO, C. M.; SANTOS, R. C. Crescimento e capacidade fotossintética da cultivar de amendoim BR1 sob condições de salinidade. Revista Brasileira de Engenharia Agrícola e Ambiental, v. 15, n. 8, p. 794-800, 2011.

LARCEDA, C. F.; SOUSA, G. G.; SILVA, F. L. B.; GUIMARÃES, F. V. A.; SILVA, G. L.; CAVALCANTE, L. F. Soil salinization and maize and cowpea yield in the crop rotation system using saline Waters. Engenharia Agrícola, v. 31, n. 4, p. 663-675, 2011.

LEITE, E. M.; CAVALCANTE, L. F.; DINIZ, A. A.; SANTOS, R. V.; ALVES, G. S.; CAVALCANTE, I. H. L. Correção da sodicidade de dois solos irrigados em resposta à aplicação de gesso agrícola. Irriga, v. 12, n. 2, p. 168-176, 2007.

MAGALÃES, A. F. Métodos de análise química para solos salinos e sódicos. Recife: UFRPE, 1987. 30p. 
MELO, R. M.; BARROS, M. de F. C.; SANTOS P. M.; ROLIM, M. M. Correção de solos salinosódicos pela aplicação de gesso mineral1. Revista Brasileira de Engenharia Agrícola e Ambiental, v. 12, n. 4, p. 376-380, 2008.

RICHARDS, L.A. Diagnosis and improvement of saline and alkali soils. Washington: .United States Department of Agriculture.U. S. Government Printing, Office, D. C., Handbook 60, 1954. 160p.

RUIZ, H. A.; SAMPAIO, R. A.; OLIVEIRA, M.; ALVAREZ VENEGAS, V. H. Características químicas de solos salino-sódicos submetidos a parcelamentos da lâmina de lixiviação. Pesquisa agropecuária brasileira, v. 39, n. 11, p. 1119-1126, 2004.

SILVA, E. F.; ASSIS JÚNIOR, R. M.; SOUSA, J. I. G. Efeito da qualidade da água de irrigação sobre atributos hídricos e um Neossolo. Revista Brasileira de Ciência do Solo, v. 29, p. 389396, 2005.

SILVA, F. L. B.; LACERDA, C. F.; SOUSA, G.
G.; NEVES, A. L. R.; SILVA, G. L.; SOUSA, C. H. C. Interação entre salinidade e biofertilizante bovino na cultura do feijão-caupi. Revista Brasileira de Engenharia Agrícola e Ambiental, v. 15, n. 4, p. 383-389, 2011.

SILVA, F. E. O.; MARACAJA, P. B.; MEDEIROS, J. F.; OLIVEIRA, F. A.; OLIVEIRA, M. K. T. Desenvolvimento vegetativo do feijão caupi irrigado com água salina em casa de vegetação. Revista Caatinga, v. 22, n. 3, p. 156-159, 2009.

SOUSA, G. G.; VIANA, T. V. A.; LACERDA, C. F.; AZEVEDO, B. M.; SILVA, G. L.; COSTA, F. R. B. Estresse salino em plantas de feijão-caupi em solo com fertilizantes orgânicos. RevistaAgro@mbiente On-line, v. 8, n. 3, p. 359-367, 2014.

TAVARES FILHO, A. N.; BARROS, M. F. C.; ROLIM, M.M.; SILVA, E.F.F. Incorporação de gesso para correção da salinidade e sodicidade de solos salino-sódicos. Revista Brasileira de Engenharia Agrícola e Ambiental, v. 16, n. 3, p. 247-252, 2012. 